\title{
Development and validation of a score for evaluating comprehensive stroke care capabilities: J-ASPECT Study
}

\author{
Akiko Kada1*, Kunihiro Nishimura², Jyoji Nakagawara ${ }^{3}$, Kuniaki Ogasawara $^{4}$, Junichi Ono ${ }^{5}$, Yoshiaki Shiokawa ${ }^{6}$, \\ Toru Aruga ${ }^{7}$, Shigeru Miyachi ${ }^{8}$, Izumi Nagata ${ }^{9}$, Kazunori Toyoda ${ }^{10}$, Shinya Matsuda ${ }^{11}$, Akifumi Suzuki ${ }^{12}$, \\ Hiroharu Kataoka ${ }^{13}$, Fumiaki Nakamura ${ }^{2}$, Satoru Kamitani ${ }^{14}$, Koji lihara ${ }^{15}$ and the J-ASPECT Study Collaborators
}

\begin{abstract}
Background: Although the Brain Attack Coalition recommended establishing centers of comprehensive care for stroke and cerebrovascular disease patients, a scoring system for such centers was lacking. We created and validated a comprehensive stroke center (CSC) score, adapted to Japanese circumstances.

Methods: Of the selected 1369 certified training institutions in Japan, 749 completed an acute stroke care capabilities survey. Hospital performance was determined using a 25-item score, evaluating 5 subcategories: personnel, diagnostic techniques, specific expertise, infrastructure, and education. Consistency and validity were examined using correlation coefficients and factorial analysis.

Results: The CSC score (median, 14; interquartile range, 11-18) varied according to hospital volume. The five subcategories showed moderate consistency (Cronbach's $a=0.765)$. A strong correlation existed between types of available personnel and specific expertise. Using the 2011 Japanese Diagnosis Procedure Combination database for patients hospitalized with stroke, four constructs were identified by factorial analysis (neurovascular surgery and intervention, vascular neurology, diagnostic neuroradiology, and neurocritical care and rehabilitation) that affected in-hospital mortality from ischemic stroke, intracerebral hemorrhage, and subarachnoid hemorrhage. The total CSC score was related to in-hospital mortality from ischemic stroke (odds ratio [OR], 0.973; 95\% confidence interval [CI], 0.958-0.989), intracerebral hemorrhage $(\mathrm{OR}, 0.970 ; 95 \% \mathrm{Cl}, 0.950-0.990)$, and subarachnoid hemorrhage (OR, $0.951 ; 95 \% \mathrm{Cl}, 0.925-0.977)$, with varying contributions from the four constructs.
\end{abstract}

Conclusions: The CSC score is a valid measure for assessing CSC capabilities, based on the availability of neurovascular surgery and intervention, vascular neurology, diagnostic neuroradiology, and critical care and rehabilitation services.

Keywords: Ischemia, Stroke, Hemorrhage, Cerebrovascular circulation, Risk factors

\section{Background}

Stroke is the fourth leading cause of mortality and the most common cause of permanent morbidity in Japan, causing an enormous socioeconomic burden. The public health implications of stroke care globally, including in Japan, are profound. Despite accelerating progress in stroke therapy, implementation of appropriate acute

\footnotetext{
* Correspondence: akiko.kada@nnh.go.jp

${ }^{1}$ Department of Clinical Trials and Research, Clinical Research Center, National Hospital Organization Nagoya Medical Center, 4-1-1 Sannomaru, Naka-ku, Nagoya, Aichi 460-0001, Japan

Full list of author information is available at the end of the article
}

treatment remains essential for decreasing the associated mortality and permanent morbidity. In 2000, the Brain Attack Coalition discussed the concept of primary stroke centers and later proposed the design of comprehensive stroke centers (CSCs) [1, 2]. Most stroke patients can be adequately treated at a primary stroke center (PSC), and the Joint Commission established programs for the certification and performance measurement of PSCs [3]. The concept and recommended key components of a CSC enable intensive patient care and the use of specialized techniques that are not available at most PSCs $[1,4]$. To continuously monitor the efficiency of care, reliable 
measures of hospital capabilities and performance are needed. Although the Joint Commission and several US states have started certification processes for PSCs and CSCs [5-8], an established, simple scoring system does not exist to evaluate the comprehensive acute stroke care capabilities of CSCs. To this end, a simple tool for assessing CSC capabilities would be useful for monitoring service quality and enabling its improvement [4]. In 2010, we started the J-ASPECT study (Nationwide survey of Acute Stroke care capacity for Proper dEsignation of Comprehensive stroke cenTer in Japan) to establish optimal nationwide implementation of stroke centers to improve acute stroke outcomes. We modified the above recommendations to reflect the specific circumstances in Japan and developed a CSC score; this tool was validated using the nationwide Diagnosis Combination Procedure (DPC) database, created during the first year of this study.

\section{Methods \\ Content validity}

In the first step of the J-ASPECT study, we investigated the current conditions of stroke hospitals in Japan. We created a 49-item questionnaire examining various aspects of stroke care, including medical systems, emergency systems, stroke rehabilitation, education, and medical performance. Some recommended items, such as ventriculostomy availability, were excluded from our questionnaire for the sake of simplicity and to increase the survey response rate since the items seemed identical to the recommendations of board-certified (BC) neurosurgeons in Japan. Other items, such as availability of transesophageal echocardiography, were excluded because of their very low expected usage, which would make an evaluation of their impact on mortality rates difficult. In February 2011, the questionnaire was mailed to 1369 certified training institutions belonging to the Japan Neurosurgical Society, the Japanese Society of Neurology, and the Japan Stroke Society. Based on this questionnaire, the overall organizational and staffing levels of the hospitals, in terms of CSC capacity, were scored following the Brain Attack Coalition recommendations, after reviewing the literature describing CSCs and conducting a thorough discussion with an expert panel [9]. Advanced acute stroke care capabilities were assessed based on 25 items divided into 5 subcategories (listed in Table 1). One point was assigned for each recommended item that the hospital met, resulting in a maximum total score of 25 ; subcategory scores were also calculated.

\section{Consistency}

Cronbach's $\alpha$ was calculated to evaluate the consistency between the 5 CSC score subcategories used for
Table 1 The availability of comprehensive stroke center score components

\begin{tabular}{|c|c|c|c|c|}
\hline Components & Items & Item No & Number & Percent \\
\hline \multirow[t]{7}{*}{ Personnel } & Neurologists & 1 & 358 & 47.8 \\
\hline & Neurosurgeons & 2 & 694 & 92.7 \\
\hline & Endovascular physicians & 3 & 272 & 36.3 \\
\hline & Critical care medicine & 4 & 162 & 21.6 \\
\hline & $\begin{array}{l}\text { Physical medicine and } \\
\text { rehabilitation }\end{array}$ & 5 & 113 & 15.1 \\
\hline & Rehabilitation therapy & 6 & 742 & 99.1 \\
\hline & Stroke rehabilitation nurses & 7 & 102 & 13.6 \\
\hline \multirow{6}{*}{$\begin{array}{l}\text { Diagnostics } \\
(24 / 7)\end{array}$} & $C T^{\mathrm{a}}$ & 8 & 742 & 99.1 \\
\hline & $M R I^{b}$ with diffusion & 9 & 647 & 86.4 \\
\hline & Digital cerebral angiography & 10 & 602 & 80.4 \\
\hline & CT angiography & 11 & 627 & 83.7 \\
\hline & Carotid duplex ultrasound & 12 & 257 & 34.3 \\
\hline & $\mathrm{TCD}^{c}$ & 13 & 121 & 16.2 \\
\hline \multirow{5}{*}{$\begin{array}{l}\text { Specific } \\
\text { expertise }\end{array}$} & Carotid endarterectomy & 14 & 603 & 80.5 \\
\hline & $\begin{array}{l}\text { Clipping of intracranial } \\
\text { aneurysm }\end{array}$ & 15 & 685 & 91.5 \\
\hline & Hematoma removal/draining & 16 & 689 & 92.0 \\
\hline & $\begin{array}{l}\text { Coiling of intracranial } \\
\text { aneurysm }\end{array}$ & 17 & 360 & 48.1 \\
\hline & $\begin{array}{l}\text { Intra-arterial reperfusion } \\
\text { therapy }\end{array}$ & 18 & 498 & 66.5 \\
\hline \multirow[t]{5}{*}{ Infrastructure } & Stroke unit & 19 & 132 & 17.6 \\
\hline & Intensive care unit & 20 & 445 & 59.4 \\
\hline & Operating room staffed 24/7 & 21 & 451 & 60.2 \\
\hline & $\begin{array}{l}\text { Interventional services } \\
\text { coverage } 24 / 7\end{array}$ & 22 & 279 & 37.2 \\
\hline & Stroke registry & 23 & 235 & 31.4 \\
\hline \multirow[t]{2}{*}{ Education } & Community education & 24 & 369 & 49.3 \\
\hline & Professional education & 25 & 436 & 58.2 \\
\hline
\end{tabular}

${ }^{a}$ computed tomography; ${ }^{b}$ magnetic resonance imaging; ${ }^{c}$ transcranial Doppler

assessing CSC capabilities. To determine the influence of each subcategory, $\alpha$-values were also calculated for all combinations of the four subcategories. Correlations between the 25 CSC score items were determined using tetrachoric correlation coefficients to evaluate individual items measured with different constructs.

\section{Construct validity}

Factorial analysis, based on tetrachoric correlation coefficients [10], was performed using principal factor analysis to explore possible potential groupings of the 25 items into a more limited number of components. The selection of the number of components was based on the Eigen values. To understand the meaning of the components, promax rotation was used. 


\section{Predictive validity}

Using the Japanese DPC database for patients hospitalized with strokes during the 2011 fiscal year, we examined the differential effects of the items on mortality and poor outcomes (modified Rankin Scale: 3-6, at discharge) associated with ischemic stroke (IS), intracerebral hemorrhage ( $\mathrm{ICH})$, and subarachnoid hemorrhage (SAH). This cross-sectional survey used the DPC discharge database for the institutions participating in the J-ASPECT study. The DPC database is a mixed-case classification system that is linked with the lump-sum payment system, launched in 2002 by the Ministry of Health, Labor and Welfare of Japan [11]. In 2010, approximately 1388 acute care hospitals, representing about $50 \%$ of the total hospital beds, had adopted the DPC data system. Data regarding practices were obtained from the DPC database; the attending physician is responsible for each patient's clinical data entry. The details of this database have been described elsewhere [12].

Of the 749 hospitals that responded to the institutional survey of advanced stroke care capabilities, 256 agreed to participate in the DPC discharge database study. Consecutive patients, hospitalized between April 1, 2010 and March 31, 2011, were identified in the annual discharge database using the International Classification of Diseases (ICD)-10 diagnosis codes related to IS (I63.0-9), nontraumatic ICH (I61.0-9, I62.0-1, I62.9), and SAH (I60.0-9). Patients with scheduled admissions were excluded from analysis. This research was approved by the Institutional Review Board of the National Cerebral and Cardiovascular Center and, if required, by the participating hospitals.

We used hierarchical logistic regression models to determine relationships between hospital CSC scores, reflecting the capacities they were equipped with, and mortality. Each model had two levels of hierarchy (hospital and patient), and considered the random effects of hospital variables as well as the fixed effects of CSC scores, patient age and sex, and Japan Coma Scale (JCS) scores. Interactions such as those between the JCS and CSC scores were not included in the model. The analyses were performed using SAS, version 9.3 (SAS Institute, Cary, NC, USA), and R, version 3.2.0 ( $\mathrm{R}$ Core Team, R Foundation for Statistical Computing, Vienna, Austria).

\section{Results}

Of the selected 1369 certified training institutions, 749 (55\%) responded to the acute stroke care capability survey. Among the surveyed hospitals, $62 \%$ had more than 300 beds, and $51 \%$ had more than 200 acute patients (Table 2). Clipping of intracranial aneurysms (IAs) was performed more frequently than any other procedure (median/hospital, 15), followed by craniotomy removal
Table 2 Hospital characteristics

\begin{tabular}{|c|c|}
\hline \multicolumn{2}{|l|}{ Beds per hospital, n (\%) } \\
\hline $20-49$ & $16(2.1)$ \\
\hline $50-99$ & $30(4.0)$ \\
\hline 100-299 & $232(31.0)$ \\
\hline $300-499$ & $260(34.7)$ \\
\hline$>500$ & $207(27.6)$ \\
\hline Unknown & $4(0.5)$ \\
\hline \multicolumn{2}{|l|}{ Acute stroke patients per hospital, n (\%) } \\
\hline$\leq 49$ & $51(6.8)$ \\
\hline $50-99$ & $78(10.4)$ \\
\hline $100-199$ & $199(26.6)$ \\
\hline $200-299$ & $155(20.7)$ \\
\hline$>300$ & $228(30.4)$ \\
\hline Unknown & $38(5.1)$ \\
\hline \multicolumn{2}{|l|}{ Treated patients per hospital, median $\left(I \mathrm{QR}^{\mathrm{a}}\right)$} \\
\hline Tissue plasminogen activator & $5(2-10)$ \\
\hline Intra-arterial thrombolysis/percutaneous angioplasty & $0(0-2)$ \\
\hline Carotid endarterectomy & $1(0-4)$ \\
\hline Carotid stenting & $1(0-7)$ \\
\hline Extracranial-intracranial bypass surgery & $1(0-5)$ \\
\hline Clipping of intracranial aneurysm & $15(6-27)$ \\
\hline Coiling of intracranial aneurysm & $3(0-11)$ \\
\hline Craniotomy hematoma removal & $6(2-12)$ \\
\hline Stereotactic hematoma removal & $0(0-3)$ \\
\hline Endoscopic hematoma removal & $0(0-0)$ \\
\hline
\end{tabular}

${ }_{\text {anterquartile range }}$

of $\mathrm{ICH}$ (6), intravenous infusion of recombinant tissue plasminogen activator (5), and coiling of IAs (3). The availability of each item is shown in Table 1. Even within the same component, the availability of each item varied. Low availability values were noted for IA coiling (48.1\%) in the specific expertise component and for stroke units $(17.6 \%)$ in the infrastructure component.

The distribution of CSC score components, by hospital, is shown in Table 3. The median CSC score was 14 (interquartile range, 11-18). These components showed moderate consistency (Cronbach's $\alpha=0.765$, for the total score). Removal of any one component resulted in Cronbach's $\alpha$ falling in the range of $0.668-0.776$, indicating the absence of substantial influence of individual components. High correlations between the survey components pertaining to personnel and specific expertise were observed (Table 4). For example, there were high correlations between neurosurgeon availability and carotid endarterectomy $(r=0.821$; items 2 and 14), clipping of IAs $(r=0.936$; items 2 and 15), and hematoma removal/ drainage $(r=0.949$; items 2 and 16). Similarly, endovascular physician availability was strongly correlated with 
Table 3 The distribution of comprehensive stroke center score components and their consistency

\begin{tabular}{lllllc}
\hline Components & Mean & SD & Median & IQR $^{\mathrm{a}}$ & Cronbach's a \\
\hline Personnel & 3.26 & 1.25 & 3 & $2-4$ & 0.724 \\
Diagnostic & 4.00 & 1.28 & 4 & $4-5$ & 0.741 \\
Specific expertise & 3.79 & 1.48 & 4 & $3-5$ & 0.668 \\
Infrastructure & 2.06 & 1.43 & 2 & $1-3$ & 0.674 \\
Education & 1.07 & 0.83 & 1 & $0-2$ & 0.776 \\
Total Score & 14.18 & 4.57 & 14 & $11-18$ & 0.765 \\
\hline
\end{tabular}

ainterquartile range

coiling of IAs ( $\mathrm{r}=0.932$; items 3 and 17) and intraarterial reperfusion therapy $(r=0.842$; items 3 and 18). Other relationships regarding diagnostics, infrastructure, and education did not stand out.

Factorial analysis, based on promax rotation, revealed four constructs (Table 5). The first pattern contained items pertaining to neurovascular surgery and intervention, such as endovascular physician availability, coiling of IAs, intra-arterial reperfusion therapy, 24/7 interventional services coverage, carotid endarterectomy, hematoma removal/drainage, clipping of IAs, neurosurgeon availability, rehabilitation therapy, 24/7 operating room staffing, and stroke rehabilitation nurse availability. The first pattern had the largest explained variance $(43 \%$ of total variance). The second pattern included imaging modalities mainly associated with diagnostic neuroradiology (e.g., computed tomography, computed tomography angiography, digital cerebral angiography, and diffusion-weighted magnetic resonance imaging) and intensive care units. The third pattern contained items related to vascular neurology: transcranial Doppler, carotid duplex ultrasound, professional education, community education, stroke registry, and available stroke units. The fourth pattern represented neurocritical care and rehabilitation, and included the availability of neurologists, physical medicine and rehabilitation, and critical care medicine.

A total of 53,170 patients in the cohort were analyzed; the in-hospital mortality was $7.8 \%$ for IS, $16.8 \%$ for ICH, and $28.1 \%$ for SAH (Table 6). Table 7 shows the impact of hospital capacity for each of the 25 items on mortality. Among the four constructs obtained using factorial analysis, the availability of neurologists in neurocritical care and rehabilitation was significantly associated with reduced mortality of patients with IS $(\mathrm{P}<0.05)$. The $24 /$ 7 availability of interventional service coverage in neurovascular surgery and intervention $(\mathrm{P}<0.05)$, availability of intensive care units in diagnostic neurology, and physical medicine and rehabilitation in neurocritical care and rehabilitation $(\mathrm{P}<0.05)$ were related to SAH mortality. The total CSC score was related to the mortality associated with IS (OR, 0.973; 95\% CI, 0.958-0.989), ICH (OR,
0.970; 95\% CI, 0.950-0.990), and SAH (OR, 0.951; 95\% CI, 0.925-0.977).

The proportions of poor outcomes (modified Rankin Scale, 3-6) were $49.2 \%$ for IS, $65.3 \%$ for $\mathrm{ICH}$, and $56.4 \%$ for SAH (Table 6). In contrast to mortality, the total CSC score was not significantly associated with poor outcomes in patients having any type of stroke (Table 8). The impact of hospital capacity for each of the 25 items on poor outcomes differed from that for mortality in some aspects. For example, among patients with IS, stroke unit availability were significantly associated with a reduced proportion of poor outcomes $(\mathrm{P}<0.05)$. Among patients with $\mathrm{ICH}$ and $\mathrm{SAH}$, no significant association was observed between the availability of any item and poor outcomes.

\section{Discussion}

We evaluated the consistency and validity of the CSC score; based on the Cronbach's $\alpha$ value of 0.765 , the five components were moderately consistent [13]. The validity of the score was evaluated using factorial analysis, which revealed four major constructs. Although the four constructs were determined by the five components: personnel, diagnostic techniques, specific expertise, infrastructure, and education, this study showed a high correlation between the survey components pertaining to personnel and specific expertise. The unique fact that $\mathrm{BC}$ neurosurgeons comprise more than $95 \%$ of $\mathrm{BC}$ endovascular physicians, in Japan, may explain why personnel, specific expertise, and infrastructure components closely related to these different treatment aspects were grouped into the same construct (neurovascular surgery and intervention). Considering their influence on the variance of the CSC scores, temporal trends and geographical disparities focused on this construct may provide critical information for proper accreditation and implementation of CSCs.

With regard to the predictive validity of the CSC score, the four constructs had different effects on mortality and poor outcomes in patients with IS, ICH, and SAH. The availability of neurologists involved in neurocritical care and rehabilitation was significantly associated with reduced in-hospital morality in patients with IS. Recently, the treatment paradigm for acute IS has been changing rapidly, such that the critical role of endovascular intervention following tissue plasminogen activator infusion, for acute IS, has been established by several recent randomized controlled trials (MR Clean, ESCAPE, EXTENDIA) [14-16]. Of note, however, the acute stroke care survey used in this study and the DPC database were both implemented before these evidences were published in 2015. The availability of BC neurosurgeons at more than $90 \%$ of the participating hospitals suggests the importance of multidisciplinary acute stroke care [17]. 


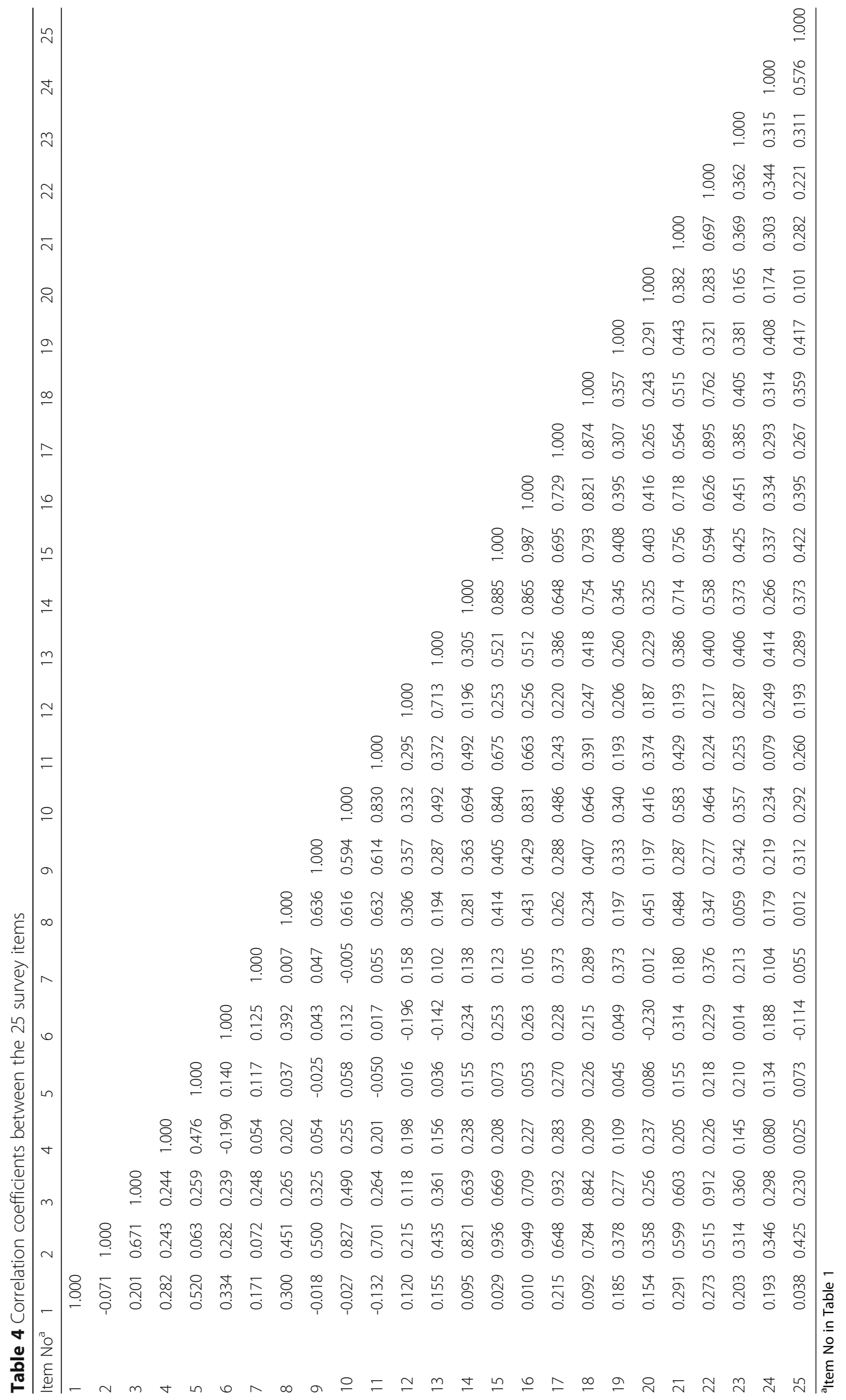


Table 5 Factor analysis

\begin{tabular}{|c|c|c|c|c|c|}
\hline & & Factor 1 & Factor 2 & Factor 3 & Factor 4 \\
\hline & & $\begin{array}{l}\text { Neurovascular surgery } \\
\text { and intervention }\end{array}$ & $\begin{array}{l}\text { Diagnostic } \\
\text { neuroradiology }\end{array}$ & Vascular neurology & $\begin{array}{l}\text { Neurocritical care } \\
\text { and rehabilitation }\end{array}$ \\
\hline & Proportion explained & 0.43 & 0.25 & 0.19 & 0.14 \\
\hline Item No & Items & Standardized loadings & ern matrix) & & \\
\hline 3 & Endovascular physicians & $0.91^{d}$ & -0.07 & -0.04 & 0.12 \\
\hline 17 & Coiling of intracranial aneurysm & 0.89 & -0.11 & 0.04 & 0.15 \\
\hline 18 & Intra-arterial reperfusion therapy & 0.88 & 0.00 & 0.10 & -0.05 \\
\hline 22 & Interventional services coverage $24 / 7$ & 0.80 & -0.09 & 0.05 & 0.23 \\
\hline 14 & Carotid endarterectomy & 0.76 & 0.24 & -0.01 & -0.10 \\
\hline 16 & Hematoma removal/draining & 0.75 & 0.37 & 0.06 & -0.16 \\
\hline 15 & Clipping of intracranial aneurysm & 0.73 & 0.37 & 0.08 & -0.16 \\
\hline 2 & Neurosurgeons & 0.69 & 0.43 & 0.02 & -0.22 \\
\hline 6 & Rehabilitation therapy & 0.59 & 0.07 & -0.63 & 0.18 \\
\hline 21 & Operating room staffed 24/7 & 0.59 & 0.28 & 0.00 & 0.18 \\
\hline 7 & Stroke rehabilitation nurses & 0.34 & -0.36 & 0.21 & 0.20 \\
\hline 8 & $C T^{a}$ & -0.03 & 0.89 & -0.21 & 0.34 \\
\hline 11 & CT angiography & 0.08 & 0.84 & 0.06 & -0.17 \\
\hline 10 & Digital cerebral angiography & 0.36 & 0.70 & 0.08 & -0.10 \\
\hline 9 & $M R I^{b}$ with diffusion & 0.03 & 0.59 & 0.23 & -0.06 \\
\hline 20 & Intensive care unit & -0.06 & 0.50 & 0.17 & 0.22 \\
\hline 13 & $\mathrm{TCD}^{\mathrm{c}}$ & 0.02 & 0.15 & 0.71 & 0.04 \\
\hline 12 & Carotid duplex ultrasound & -0.31 & 0.26 & 0.72 & 0.16 \\
\hline 25 & Professional education & 0.23 & -0.15 & 0.63 & -0.23 \\
\hline 24 & Community education & 0.21 & -0.17 & 0.56 & 0.07 \\
\hline 23 & Stroke registry & 0.24 & -0.08 & 0.52 & 0.10 \\
\hline 19 & Stroke unit & 0.23 & -0.05 & 0.49 & 0.06 \\
\hline 1 & Neurologists & -0.02 & -0.02 & 0.02 & 0.85 \\
\hline 5 & Physical medicine and rehabilitation & 0.10 & -0.09 & 0.00 & 0.72 \\
\hline 4 & Critical care medicine & -0.09 & 0.25 & 0.14 & 0.55 \\
\hline
\end{tabular}

${ }^{\mathrm{a}}$ computed tomography; ${ }^{\mathrm{b}}$ magnetic resonance imaging; ${ }^{c}$ transcranial Doppler; ${ }^{d}$ values $>0.300$ are shown in bold font

The association between the availability of a stroke care unit and the increased proportion of favorable outcomes after IS, observed in this study, is consistent with a 2009 Cochrane review conducted by the Stroke Unit Trialists' Collaboration that showed the benefits of stroke unit care in terms of reducing death, dependency, and institutional care [18].

The SAH-associated mortality was higher than that associated with IS or ICH, and the condition of the patients with SAH was also more severe and required more urgent intervention. Accordingly, the availability of items representing $\mathrm{SAH}$ treatment, such as $24 / 7$ interventional service coverage, intensive care unit, and $\mathrm{BC}$ physical medicine and rehabilitation, showed the greatest effects on mortality. The critical role of endovascular coil embolization for ruptured IAs was previously established by the International Subarachnoid Aneurysms Trial [19]. Using Nationwide Inpatient Survey data, Qureshi et al. reported a significant increase in endovascular treatment as well as a decrease in inhospital mortality (2000-2002, 27\%; 2004-2006, 24\%) in patients with SAH after publication of the International Subarachnoid Trial (ISAT) in 2002 [20]. However, whether the ISAT results can be generalized to all patients with SAH is questionable because most of the patients enrolled in the study were patients with good clinical grades, having small, anterior circulation aneurysms.

The second common cause of SAH-related death and poor functional outcome is rebleeding [21], and early treatment of the ruptured aneurysm is known to lower the incidence of rebleeding. Intensive care unit and 24/7 
Table 6 Demographics of the patient cohort at diagnosis, mortality, and severe disability at discharge

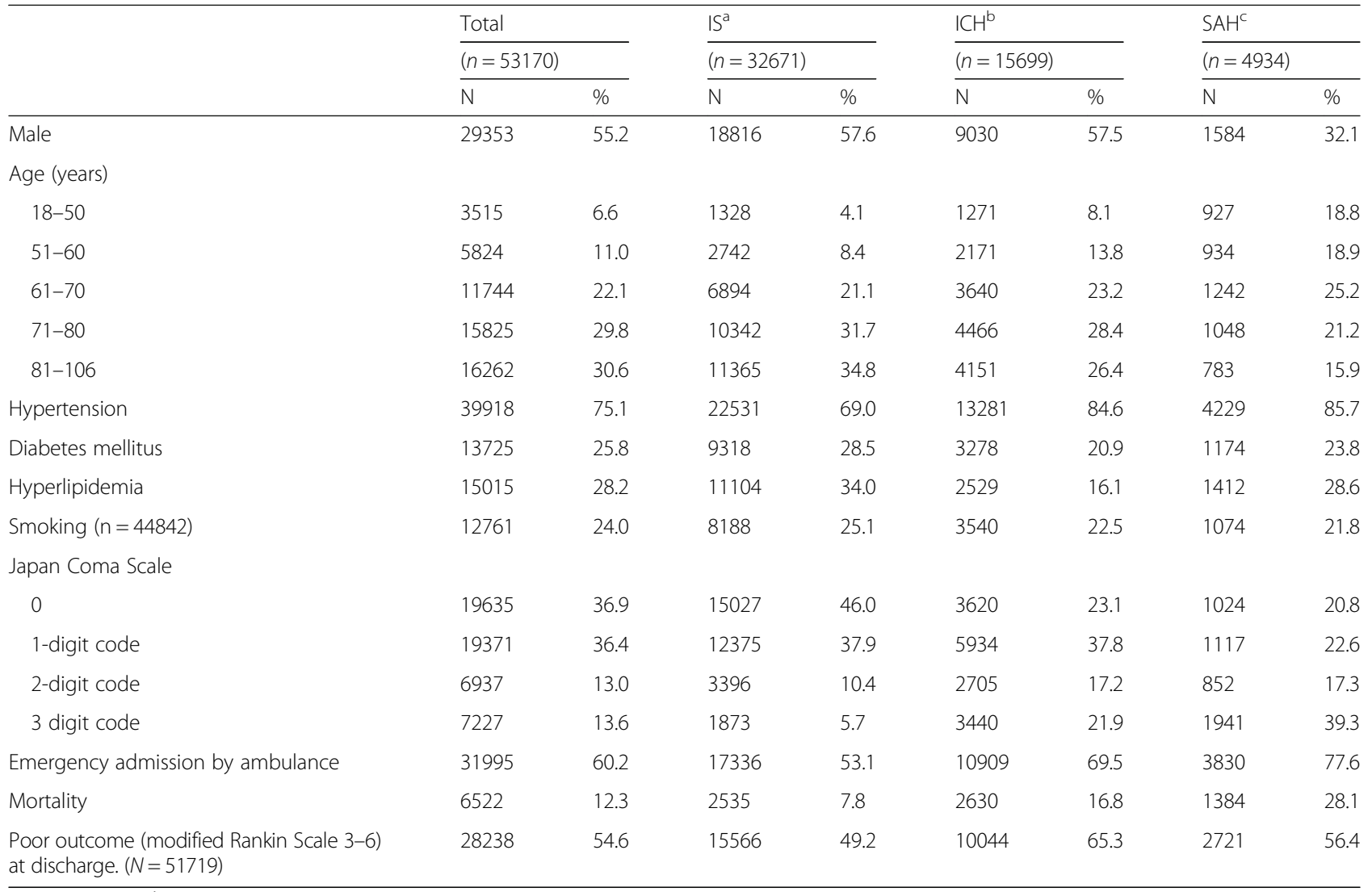

${ }^{\text {aischemic stroke; }}{ }^{\text {bintracerebral hemorrhage; }}{ }^{c}$ subarachnoid hemorrhage

interventional coverage availability were significant factors associated with decreasing in-hospital mortality after SAH. These findings are explained by the importance of early obliteration of ruptured aneurysms for preventing rebleeding and by the early detection and appropriate treatment of vasospasms, another important cause of morbidity and mortality in patients with SAH. The study provided additional evidence that the availability of endovascular treatment and surgical clipping may reduce in-hospital mortality in patients with SAH [22]. Another recent study also showed that an early mobilization program for patients with aneurysmal SAH is feasible and safe [23]. In addition, appropriate nutritional care from the acute stage is reported to be essential for improving functional outcomes and reducing post-SAH mortality [24]. Taken together, the significant association between the availability of $\mathrm{BC}$ physical medicine and rehabilitation and reduced mortality observed in our study reinforces the importance of comprehensive care capabilities, including early rehabilitation and nutritional care for patients with $\mathrm{SAH}$, to prevent complications. Further investigation is required to understand the role of $\mathrm{BC}$ physical medicine and rehabilitation in reducing $\mathrm{SAH}$ associated mortality.
Finally, the total CSC score correlated with reduced mortality for all types of stroke, supporting the usefulness of this score as a comprehensive measure of acute stroke care capabilities. Another study showed that hemorrhagic stroke patients admitted to CSCs were more likely to receive neurosurgical and endovascular treatments and to be alive at 90 days than patients admitted to other hospitals. The authors used certification by the New Jersey Department of Health and Senior Services to identify CSCs. The impacts of CSCs on mortality determined in that study are similar to the results obtained using our simple scoring system [25].

In contrast to its impact on in-hospital mortality, the total CSC score did not show a significant impact on poor functional outcomes in patients with any type of stroke. Similarly, no specific item had a significant impact on poor outcomes in patients with hemorrhagic stroke. In patients with IS, the significant role of the presence of a stroke unit in reducing poor outcomes, observed in the present study, was consistent with the results of a previous report [26]. A validation study investigating functional outcomes using the DPC database may be necessary to explain the disparities between the total CSC scores (and specific items) on mortality and poor functional outcomes. 
Table 7 The effect of items on mortality

\begin{tabular}{|c|c|c|c|c|c|c|c|c|c|c|}
\hline \multirow{4}{*}{$\begin{array}{l}\text { Item } \\
\text { No } \\
3\end{array}$} & \multirow{4}{*}{$\begin{array}{l}\text { Items } \\
\text { Endovascular physicians }\end{array}$} & \multirow{2}{*}{\multicolumn{3}{|c|}{$(n=32671)^{1 S^{\mathrm{a}}}$}} & \multirow{2}{*}{\multicolumn{3}{|c|}{$(n=15699)$}} & \multicolumn{3}{|c|}{$\mathrm{SAH}^{\mathrm{c}}$} \\
\hline & & & & & & & & \multicolumn{3}{|c|}{$(n=4934)$} \\
\hline & & \multirow{2}{*}{$\begin{array}{l}\mathrm{OR}^{\mathrm{d}} \\
0.832\end{array}$} & \multicolumn{2}{|c|}{$95 \% \mathrm{Cl}^{\mathrm{e}}$} & \multirow{2}{*}{$\begin{array}{l}O R \\
0.896\end{array}$} & \multicolumn{2}{|c|}{$95 \% \mathrm{Cl}$} & \multirow{2}{*}{$\frac{\text { OR }}{1.309}$} & \multicolumn{2}{|c|}{$95 \% \mathrm{Cl}$} \\
\hline & & & 0.653 & 1.060 & & 0.671 & 1.198 & & 0.906 & 1.891 \\
\hline 17 & Coiling of intracranial aneurysm & 1.062 & 0.832 & 1.355 & 1.075 & 0.797 & 1.451 & 0.982 & 0.667 & 1.444 \\
\hline 18 & Intra-arterial reperfusion therapy & 1.155 & 0.931 & 1.434 & 0.919 & 0.706 & 1.194 & 0.854 & 0.608 & 1.201 \\
\hline 22 & Interventional services coverage $24 / 7$ & 1.071 & 0.831 & 1.379 & 1.145 & 0.844 & 1.555 & $0.674^{j}$ & 0.458 & 0.992 \\
\hline 14 & Carotid endarterectomy & 0.945 & 0.708 & 1.262 & 0.833 & 0.595 & 1.165 & 0.789 & 0.503 & 1.237 \\
\hline 15 and 16 & $\begin{array}{l}\text { Clipping of intracranial aneurysm } \\
\text { and hematoma removal/draining }\end{array}$ & 0.798 & 0.465 & 1.368 & 0.537 & 0.266 & 1.088 & 0.359 & 0.082 & 1.564 \\
\hline 2 & Neurosurgeons & 0.905 & 0.530 & 1.546 & 1.513 & 0.744 & 3.077 & 0.840 & 0.230 & 3.071 \\
\hline 6 & Rehabilitation therapy & 1.000 & & & 1.000 & & & 1.000 & & \\
\hline 21 & Operating room staffed 24/7 & 0.986 & 0.826 & 1.176 & 0.956 & 0.769 & 1.187 & 1.217 & 0.921 & 1.610 \\
\hline 7 & Stroke rehabilitation nurses & 1.021 & 0.831 & 1.253 & 1.019 & 0.803 & 1.293 & 1.074 & 0.803 & 1.436 \\
\hline 8 & $C T^{f}$ & 0.963 & 0.208 & 4.462 & 0.515 & 0.035 & 7.590 & 1.000 & & \\
\hline 11 & CT angiography & 1.127 & 0.877 & 1.449 & 0.820 & 0.608 & 1.107 & 0.978 & 0.662 & 1.446 \\
\hline 10 & Digital cerebral angiography & 0.840 & 0.652 & 1.082 & 1.243 & 0.917 & 1.684 & 1.068 & 0.722 & 1.580 \\
\hline 9 & $M R I^{9}$ with diffusion & 1.117 & 0.849 & 1.471 & 0.844 & 0.605 & 1.176 & 0.897 & 0.581 & 1.383 \\
\hline 20 & Intensive care unit & 1.032 & 0.897 & 1.188 & 0.964 & 0.813 & 1.144 & $0.795^{j}$ & 0.640 & 0.988 \\
\hline 13 & $\mathrm{TCD}^{\mathrm{h}}$ & 0.852 & 0.699 & 1.038 & 0.879 & 0.700 & 1.105 & 1.222 & 0.930 & \\
\hline 12 & Carotid duplex ultrasound & 1.039 & 0.889 & 1.215 & 1.021 & 0.849 & 1.228 & 1.119 & 0.891 & 1.406 \\
\hline 25 & Professional education & 0.907 & 0.765 & 1.076 & 1.061 & 0.868 & 1.296 & 0.954 & 0.751 & 1.212 \\
\hline 24 & Community education & 0.948 & 0.810 & 1.109 & 0.908 & 0.753 & 1.094 & 0.800 & 0.636 & 1.006 \\
\hline 23 & Stroke registry & 0.895 & 0.781 & 1.026 & 0.861 & 0.732 & 1.013 & 0.915 & 0.749 & 1.118 \\
\hline 19 & Stroke unit & 0.993 & 0.838 & 1.177 & 0.887 & 0.724 & 1.086 & 0.871 & 0.679 & 1.118 \\
\hline 1 & Neurologists & $0.854^{j}$ & 0.742 & 0.982 & 1.043 & 0.881 & 1.234 & 1.110 & 0.901 & 1.367 \\
\hline 5 & Physical medicine and rehabilitation & 1.025 & 0.844 & 1.245 & 0.976 & 0.777 & 1.225 & $0.746^{j}$ & 0.562 & 0.991 \\
\hline \multirow[t]{2}{*}{4} & Critical care medicine & 0.967 & 0.825 & 1.134 & 0.993 & 0.823 & 1.200 & 0.895 & 0.712 & 1.126 \\
\hline & Total CSCi score & $0.973^{j}$ & 0.958 & 0.989 & $0.970^{j}$ & 0.950 & 0.990 & $0.951^{j}$ & 0.925 & 0.977 \\
\hline
\end{tabular}

${ }^{a}$ ischemic stroke; ${ }^{b}$ intracerebral hemorrhage; ${ }^{c}$ subarachnoid hemorrhage; ${ }^{\mathrm{d}} O R$ odds ratio adjusted by hierarchical logistic model including patient age, sex, Japan Coma Scale scores, and hospital variables; ${ }^{\mathrm{e}} \mathrm{Cl}$ confidence interval; ${ }^{\mathrm{f}}$ computed tomography; ${ }^{\mathrm{g}}$ magnetic resonance imaging; ${ }^{\mathrm{h}}$ transcranial Doppler; ${ }^{\mathrm{i}}$ comprehensive stroke center; ${ }^{j} P<0.05$ (hierarchical logistic model)

\section{Strengths and limitations of the present study}

First, this study is limited by a possible selection bias because hospitals actively working to improve stroke care were more likely to respond to the questionnaire. However, the coverage of the J-ASPECT Study group, which collaborates with the Japan Neurosurgical Society and the Japanese Congress of Neurological Surgeons, was broad enough to provide a reliable study sample. Second, information bias might have existed (self-reporting, recall, and nonresponse). Third, the CSC score mainly evaluated structural measures and did not consider their utilization, supported with real data. To assess clinical practice quality, the use of process measures is preferred [27], but process measures, such as electrocardiogram monitoring and pulse oximetry, were not considered in this scoring system $[4,28]$. However, strong correlations between survey components pertaining to personnel and specific expertise (e.g., availability of neurosurgeons and carotid endarterectomy) were observed in this study, suggesting that these items may not be considered as purely structural, but may have characteristics of both structural and process measures. We are planning to develop a new registry system in the J-ASPECT Study to include key metrics required for certification of CSCs in the US, in addition to the DPC database, to study and monitor the association of such quality metrics on mortality and morbidity of acute stroke patients, in Japan. Fourth, in-hospital mortality was selected as an outcome measure to test the validity of the CSC score. A recent systematic review showed that hospital mortality does not necessarily reflect the quality of clinical practice because mortality is affected 
Table 8 The effect of items on poor outcome (modified Rankin Scale 3-6)

\begin{tabular}{|c|c|c|c|c|c|c|c|c|c|c|}
\hline \multicolumn{2}{|l|}{ Item } & & \multicolumn{3}{|c|}{$\mathrm{ICH}^{\mathrm{b}}$} & \multicolumn{3}{|c|}{$\mathrm{SAH}^{\mathrm{C}}$} \\
\hline \multirow[t]{2}{*}{ No } & \multirow[t]{2}{*}{ Items } & \multicolumn{3}{|c|}{$(n=31640)$} & \multicolumn{3}{|c|}{$(n=15391)$} & \multicolumn{3}{|c|}{$(n=4821)$} \\
\hline & & \multirow{2}{*}{$\begin{array}{l}\mathrm{OR}^{\mathrm{d}} \\
1.180\end{array}$} & \multicolumn{2}{|c|}{$95 \% \mathrm{Cl}^{\mathrm{e}}$} & \multirow{2}{*}{$\begin{array}{l}\mathrm{OR} \\
0.896\end{array}$} & \multicolumn{2}{|c|}{$95 \% \mathrm{Cl}$} & \multirow{2}{*}{$\frac{\mathrm{OR}}{1.267}$} & \multicolumn{2}{|c|}{$95 \% \mathrm{Cl}$} \\
\hline 3 & Endovascular physicians & & 0.890 & 1.563 & & 0.671 & 1.198 & & 0.856 & 1.875 \\
\hline 17 & Coiling of intracranial aneurysm & 0.838 & 0.634 & 1.106 & 1.075 & 0.797 & 1.451 & 0.933 & 0.618 & 1.407 \\
\hline 18 & Intra-arterial reperfusion therapy & 0.990 & 0.777 & 1.261 & 0.919 & 0.706 & 1.194 & 0.704 & 0.487 & 1.017 \\
\hline 22 & Interventional services coverage $24 / 7$ & 0.969 & 0.725 & 1.295 & 1.145 & 0.844 & 1.555 & 0.928 & 0.615 & 1.400 \\
\hline 14 & Carotid endarterectomy & 1.293 & 0.946 & 1.768 & 0.833 & 0.595 & 1.165 & 0.838 & 0.511 & 1.376 \\
\hline 15 and 16 & $\begin{array}{l}\text { Clipping of intracranial aneurysm } \\
\text { and hematoma removal/draining }\end{array}$ & 0.763 & 0.427 & 1.364 & 0.537 & 0.266 & 1.088 & 0.553 & 0.065 & 4.693 \\
\hline 2 & Neurosurgeons & 1.026 & 0.582 & 1.807 & 1.513 & 0.744 & 3.077 & 4.449 & 0.987 & 20.041 \\
\hline 6 & Rehabilitation therapy & 1.000 & & . & 1.000 & . & & 1.000 & . & \\
\hline 21 & Operating room staffed $24 / 7$ & 0.883 & 0.723 & 1.078 & 0.956 & 0.769 & 1.187 & 0.959 & 0.712 & 1.290 \\
\hline 7 & Stroke rehabilitation nurses & 0.874 & 0.693 & 1.101 & 1.019 & 0.803 & 1.293 & 0.877 & 0.641 & 1.200 \\
\hline 8 & $C T^{f}$ & 1.328 & 0.296 & 5.956 & 0.515 & 0.035 & 7.590 & 1.000 & . & \\
\hline 11 & $\mathrm{CT}$ angiography & 1.227 & 0.931 & 1.617 & 0.820 & 0.608 & 1.107 & 0.877 & 0.579 & 1.329 \\
\hline 10 & Digital cerebral angiography & 0.912 & 0.685 & 1.213 & 1.243 & 0.917 & 1.684 & 1.274 & 0.842 & 1.928 \\
\hline 9 & $M R I^{9}$ with diffusion & 0.940 & 0.706 & 1.252 & 0.844 & 0.605 & 1.176 & 0.793 & 0.490 & 1.284 \\
\hline 20 & Intensive care unit & 0.987 & 0.842 & 1.156 & 0.964 & 0.813 & 1.144 & 1.000 & 0.795 & 1.259 \\
\hline 13 & $T C D^{h}$ & 0.966 & 0.773 & 1.208 & 0.879 & 0.700 & 1.105 & 1.152 & 0.858 & 1.547 \\
\hline 12 & Carotid duplex ultrasound & 1.183 & 0.988 & 1.415 & 1.021 & 0.849 & 1.228 & 1.206 & 0.945 & 1.538 \\
\hline 25 & Professional education & 0.892 & 0.737 & 1.079 & 1.061 & 0.868 & 1.296 & 1.015 & 0.782 & 1.317 \\
\hline 24 & Community education & 1.144 & 0.957 & 1.368 & 0.908 & 0.753 & 1.094 & 0.871 & 0.680 & 1.116 \\
\hline 23 & Stroke registry & 0.981 & 0.840 & 1.146 & 0.861 & 0.732 & 1.013 & 0.860 & 0.695 & 1.065 \\
\hline 19 & Stroke unit & $0.783^{j}$ & 0.645 & 0.952 & 0.887 & 0.724 & 1.086 & 0.878 & 0.676 & 1.141 \\
\hline 1 & Neurologists & 1.137 & 0.969 & 1.335 & 1.043 & 0.881 & 1.234 & 1.096 & 0.877 & 1.370 \\
\hline 5 & Physical medicine and rehabilitation & 1.163 & 0.934 & 1.449 & 0.976 & 0.777 & 1.225 & 0.979 & 0.725 & 1.322 \\
\hline \multirow[t]{2}{*}{4} & Critical care medicine & 1.113 & 0.929 & 1.334 & 0.993 & 0.823 & 1.200 & 1.062 & 0.830 & 1.360 \\
\hline & Total CSC score & 0.995 & 0.977 & 1.014 & 1.007 & 0.984 & 1.030 & 0.978 & 0.950 & 1.008 \\
\hline
\end{tabular}

aischemic stroke; ${ }^{b}$ intracerebral hemorrhage; ${ }^{c}$ subarachnoid hemorrhage; ${ }^{\mathrm{d}} O R$ odds ratio adjusted by hierarchical logistic model including patient age, sex, Japan Coma Scale scores, and hospital variables; ${ }^{\mathrm{e}} \mathrm{Cl}$ : confidence interval; ${ }^{\mathrm{f}}$ computed tomography; ${ }^{\mathrm{g}}$ magnetic resonance imaging; ${ }^{\mathrm{h}}$ transcranial Doppler; ${ }^{\mathrm{i}}$ comprehensive stroke center; ${ }^{j} P<0.05$ (hierarchical logistic model)

to a greater extent by the patients' condition rather than by the quality of practice [29]. Possible correlations between specific items and mortality in patients with IS may have been missed because of the relatively low in-hospital mortality associated with these patients; a larger study is necessary to resolve this issue. Fifth, the DPC-based payment system contains limited information regarding patient condition severity beyond postdischarge data and the National Institute of Health Stroke (NIHSS) Scale, Glasgow Coma Scale (GCS), ICH, or Hunt-Hess severity scores, upon admission. Nevertheless, the JCS is a useful tool for evaluating stroke severity. Notably, the importance of the JCS, published in 1974, for predicting stroke outcomes has been recently reconfirmed $[9,30]$. Further study is necessary to validate the results of the present study with other patient-level measurements, such as the NIHSS, GCS, etc. Despite the above limitations, clear correlations were revealed between the CSC score and in-hospital mortality in patients with all types of strokes. In future work, the score's components should be weighted according to stroke type, based on their influence on patient outcomes.

\section{Conclusions}

The CSC score is a valid measure for assessing the capabilities of CSCs with regard to the availability of neurovascular surgery and intervention, vascular neurology, diagnostic neuroradiology, and neurocritical care and rehabilitation. The total CSC score was associated with mortality in patients with IS, ICH, and $\mathrm{SAH}$, with varying contributions from the four abovementioned constructs. 


\section{Abbreviations}

BC: Board-certified; Cl: Confidence interval; CSC: Comprehensive stroke center; DPC: Diagnosis combination procedure; GCS: Glasgow coma scale; IA: Intracranial aneurysm; ICH: Intracerebral hemorrhage; IS: Ischemic stroke; ISAT: International subarachnoid trial; JCS: Japan coma scale; NIHSS: National institute of health stroke; OR: Odds ratio; PSC: Primary stroke center; $\mathrm{SAH}$ : Subarachnoid hemorrhage

\section{Acknowledgements}

We thank Drs. Manabu Hasegawa, Tomoatsu Tsuji, and Yasuhiro Nishijima for their helpful discussions, Profs. Takamasa Kayama and Nobuo Hashimoto for their supervision of the Japan Neurosurgical Society collaboration, and Ms. Arisa Ishitoko for her secretarial assistance.

\section{Funding}

This work was supported by Grants-in-Aid from the Ministry of Health, Labor and Welfare of Japan and JSPS KAKENHI Grant Number 25293314 (principal investigator: KI). This research was partially supported by the Practical Research Project for Life-Style related Diseases, including Cardiovascular Diseases and Diabetes Mellitus, from the Japan Agency for Medical Research and Development.

\section{Availability of data and materials}

The datasets for this manuscript will not be shared, based on agreements between the principal investigator and the presidents of the participating hospitals.

\section{Authors' contributions}

$\mathrm{KI}$ initiated the collaborative project. AK, KN, SK, and KI designed the study, drafted and revised the article. AK, KN, SK monitored data collection and analyzed the data. JN, KO, JO, YS, TA, SM, IN, KT, SM, AS, HK, FN designed the study, and validated the survey questions from the views of physicians and experts. All authors read and approved the final manuscript.

\section{Competing interests}

$\mathrm{Kl}$ has received grants from Nihon Medi-Physics, AstraZeneca, and Otsuka Pharmaceutical. JN has received an unrestricted research grant from Nihon Medi-Physics. IN has received lecture honoraria from Otsuka Pharmaceutical and Sanofi.

\section{Consent for publication}

Not applicable.

\section{Ethics approval and consent to participate}

Ethical approval was provided by National Cerebral and Cardiovascular Center in Japan.

\footnotetext{
Author details

${ }^{1}$ Department of Clinical Trials and Research, Clinical Research Center, National Hospital Organization Nagoya Medical Center, 4-1-1 Sannomaru, Naka-ku, Nagoya, Aichi 460-0001, Japan. ${ }^{2}$ Center for Cardiovascular Disease Information, National Cerebral and Cardiovascular Center, Suita, Japan. ${ }^{3}$ Integrative Stroke Imaging Center, National Cerebral and Cardiovascular Center, Suita, Japan. ${ }^{4}$ Department of Neurosurgery, Iwate Medical University, Morioka, Japan. ${ }^{5}$ Chiba Cardiovascular Center, Ichihara, Japan. ${ }^{6}$ Department of Neurosurgery, Kyorin University, Mitaka, Japan. ${ }^{7}$ Showa University, Tokyo, Japan. ${ }^{8}$ Department of Neurosurgery, Osaka Medical College, Takatsuki, Japan. ${ }^{9}$ Kokura Memorial Hospital, Fukuoka, Japan. ${ }^{10}$ Departments of Cerebrovascular Medicine, Nationa Cerebral and Cardiovascular Center, Suita, Japan. ${ }^{11}$ Department of Preventive Medicine and Community Health, University of Occupational and Environmental Health, Kita-Kyushu, Japan. ${ }^{12}$ Akita Prefectural Hospital Organization Research Institute for Brain and Blood Vessels, Akita, Japan. ${ }^{13}$ Department of Neurosurgery, National Cerebral and Cardiovascular Center, Suita, Japan. ${ }^{14}$ Department of Public Health, Graduate School of Medicine, The University of Tokyo, Tokyo, Japan. ${ }^{15}$ Department of Neurosurgery, Graduate School of Medical Sciences, Kyushu University, Fukuoka, Japan.
}

Received: 25 July 2016 Accepted: 8 February 2017

Published online: 28 February 2017

\section{References}

1. Alberts MJ, Hademenos G, Latchaw RE, Jagoda A, Marler JR, Mayberg MR, et al. Recommendations for the establishment of primary stroke centers. Brain Attack Coalition. JAMA. 2000:283:3102-9.

2. Alberts MJ, Latchaw RE, Selman WR, Shephard T, Hadley MN, Brass LM, et al. Recommendations for comprehensive stroke centers: a consensus statement from the Brain Attack Coalition. Stroke. 2005;36:1597-616.

3. Reeves MJ, Parker C, Fonarow GC, Smith EE, Schwamm LH. Development of stroke performance measures: definitions, methods, and current measures. Stroke. 2010;41:1573-8.

4. Leifer D, Bravata DM, Connors 3rd JJ, Hinchey JA, Jauch EC, Johnston SC, et al. Metrics for measuring quality of care in comprehensive stroke centers: detailed follow-up to Brain Attack Coalition comprehensive stroke center recommendations: a statement for healthcare professionals from the American Heart Association/American Stroke Association. Stroke. 2011:42:849-77.

5. Markovchick VJ, Moore EE. Optimal trauma outcome: trauma system design and the trauma team. Emerg Med Clin North Am. 2007:25:643-54.

6. Joint Commission on Accreditation of Healthcare Organizations. Updated Primary Stroke Center Certification appendix for the disease-specific care manual. Jt Comm Perspect. 2005;25:3-6

7. Gropen TI, Gagliano PJ, Blake CA, Sacco RL, Kwiatkowski T, Richmond NJ, et al. Quality improvement in acute stroke: the New York State Stroke Center Designation Project. Neurology. 2006;67:88-93.

8. Stradling D, Yu W, Langdorf ML, Tsai F, Kostanian V, Hasso AN, et al. Stroke care delivery before vs after JCAHO stroke center certification. Neurology. 2007:68:469-70

9. lihara K, Nishimura K, Kada A, Nakagawara J, Toyoda K, Ogasawara K, et al. The impact of comprehensive stroke care capacity on the hospital volume of stroke interventions: a nationwide study in Japan: J-ASPECT Study. J Stroke Cerebrovasc Dis. 2014;23:1001-18.

10. Kubinger $\mathrm{KD}$. On artificial results due to using factor analysis for dichotomous variables. Psychol Sci. 2003:45:106-10.

11. Yasunaga $H$, Ide $H$, Imamura $T$, Ohe $K$. Impact of the Japanese Diagnosis Procedure Combination-based Payment System on cardiovascular medicinerelated costs. Int Heart J. 2005;46:855-66.

12. lihara K, Nishimura K, Kada A, Nakagawara J, Ogasawara K, Ono J, et al. Effects of comprehensive stroke care capabilities on in-hospital mortality of patients with ischemic and hemorrhagic stroke: J-ASPECT Study. PLoS ONE. 2014;9:e96819.

13. Terwee $C B$, Bot SD, de Boer MR, van der Windt DA, Knol DL, Dekker J, et al. Quality criteria were proposed for measurement properties of health status questionnaire. J Clin Epidemiol. 2007;60:34-42.

14. Berkhemer OA, Fransen PS, Beumer D, van den Berg LA, Lingsma HF, Yoo AJ, et al. A randomized trial of intraarterial treatment for acute ischemic stroke. N Engl J Med. 2015:372:11-20.

15. Goyal M, Demchuk AM, Menon BK, Eesa M, Rempel JL, Thornton J, et al. Randomized assessment of rapid endovascular treatment of ischemic stroke. N Engl J Med. 2015:372:1019-30.

16. Campbell BC, Mitchell PJ, Kleinig TJ, Dewey HM, Churilov L, Yassi N, et al. Endovascular therapy for ischemic stroke with perfusion-imaging selection. N Engl J Med. 2015;372:1009-18.

17. Decker C, Chhatriwalla E, Gialde E, Garavalia B, Summers D, Quinlan ME, et al. Patient-centered decision support in acute ischemic stroke: Qualitative study of patients' and providers' perspectives. Circ Cardiovasc Qual Outcomes. 2015;8 Suppl 3:S109-16.

18. Sun Y, Paulus D, Eyssen M, Maervoet J, Saka O. A systematic review and meta-analysis of acute stroke unit care: what's beyond the statistical significance? BMC Med Res Methodol. 2013;13:132

19. Molyneux AJ, Kerr RS, Yu LM, Clarke M, Sneade M, Yarnold JA, et al. International subarachnoid aneurysm trial (ISAT) of neurosurgical clipping versus endovascular coiling in 2143 patients with ruptured intracranial aneurysms: a randomized comparison of effect on survival, dependency, seizures, rebleeding, subgroups, and aneurysm occlusion. Lancet. 2005; 366:809-17

20. Qureshi Al, Vazquez G, Tariq N, Suri MF, Lakshminarayan K, Lanzino G. Impact of International Subarachnoid Aneurysm Trial results on treatment of ruptured intracranial aneurysms in the United States. Clinical article. J Neurosurg. 2011;114:834-41. 
21. Broderick JP, Brott TG, Duldner JE, Tomsick T, Leach A. Initial and recurrent bleeding are the major causes of death following subarachnoid hemorrhage. Stroke. 1994;25:1342-7.

22. Spetzler RF, McDougall CG, Albuquerque FC, Zabramski JM, Hills NK, Partovi S, et al. The Barrow Ruptured Aneurysm Trial: 3-year results. J Neurosurg. 2013;119:146-57.

23. Olkowski BF, Devine MA, Slotnick LE, Veznedaroglu E, Liebman KM, Arcaro ML, et al. Safety and feasibility of an early mobilization program for patients with aneurysmal subarachnoid hemorrhage. Phys Ther. 2013;93:208-15.

24. Nagano A, Yamada Y, Miyake H, Domen K, Koyama T. Increased resting energy expenditure after endovascular coiling for subarachnoid hemorrhage. J Stroke Cerebrovasc Dis. 2016;25:813-8.

25. McKinney JS, Cheng JQ, Rybinnik I, Kostis JB, for the Myocardical Infarction Data Acquisition System Study Group. Comprehensive stroke centers may be associated with improved survival in hemorrhagic stroke. J Am Heart Assoc 2015:4:e001448.

26. Minematsu K, Uehara T, Yasui N, Hata T, Ueda T, Okada Y, et al. Effects of stroke unit on patient outcome: a prospective multicenter study in Japan. Jpn J Stroke. 2007;29:59-64.

27. Lilford RJ, Brown CA, Nicholl J. Use of process measures to monitor the quality of clinical practice. BMJ. 2007;335:648-50.

28. Uehara T, Yasui N, Okada Y, Hasegawa Y, Nagatsuka K, Minematsu K. Which should be the essential components of stroke centers in Japan? A survey by questionnaires sent to the directors of facilities certified by the Japan Stroke Society. Cerebrovasc Dis. 2014;37:409-16.

29. Pitches DW, Mohammed AM, Lilford RJ. What is the empirical evidence that hospitals with higher-risk adjusted mortality rates provide poorer quality care? A systematic review of the literature. BMC Health Serv Res. 2007;7:91.

30. Shigematsu K, Nakano H, Watanabe $\mathrm{Y}$. The eye response test alone is sufficient to predict stroke outcome-reintroduction of Japan Coma Scale: A cohort study. BMJ Open. 2013;3:e002736.

\section{Submit your next manuscript to BioMed Central and we will help you at every step:}

- We accept pre-submission inquiries

- Our selector tool helps you to find the most relevant journal

- We provide round the clock customer support

- Convenient online submission

- Thorough peer review

- Inclusion in PubMed and all major indexing services

- Maximum visibility for your research

Submit your manuscript at www.biomedcentral.com/submit 